\title{
LAS ESTELAS DEL SUROESTE COMO HITOS DE VIAS GANADERAS Y RUTAS COMERCIALES
}

\author{
POR \\ MARISA RUIZ-GALVEZ PRIEGO (*) \\ EDUARDO GALAN DOMINGO (**)
}

RESUMEN Este trabajo plantea la interpretación de las Estelas del Suroeste no como tumbas, sino como hitos de referencia, visibles en el paisaje y que marcan recursos y vías de paso, necesarios para quienes, como ganaderos y comerciantes, se desplazen por el territorio. Muchas de ellas parecen emplazarse en la intersección de dos zonas ecológicas complementarias, e incluso marcar límites territoriales.

ABSTRACT This paper is concerned with the Stelae of Southwest Spain. Tradicionally, they have been associated with tombs, but we propose here to consider them as landmarkers, recognizable in the landscape, and signalling resources and routes. They seem to be located at the edge of two complementary ecological zones, and they even mark territorial boundaries. This view is coherent with the importance that cattle and trade had in the economy of this time.

Palabras clave Estelas del Suroeste. Bronce Final. Hitos. Vías. Comercio. Paisaje.

Key words Southwest Stelae. Late Bronze Age. Landmarkers. Routes. Trade. Landscape.

\section{INTRODUCCION}

Las estelas decoradas o de guerrero son uno de los elementos más representativos del Bronce Final de la región suroccidental de la Península Ibérica. A partir el primer y magnífico Corpus realizado por Almagro Basch (1966), repetidos ensayos (Pingel, 1974; Varela y Pinho, 1977; Almagro Gorbea, 1977; Barceló, 1989) han analizado desde distintas ópticas su carácter formal y la combinación de atributos con una visión evolutiva que atribuía por lo general una mayor antigüedad a

(`) Prof esora Titular. Departamento de Prehistoria. Universidad Complutense.

(**) Becario Predoctoral. Departamento de Prehistoria. Universidad Complutense. 
aquéllas cuyos elementos eran más simples que a aquellas otras que mostraban una rica presencia de ellos, destacando la de la figura humana. En algún caso se ha acudido para ello a pretendidas identificaciones de las armas representadas como espadas pistiliformes o en lengua de carpa, lo cual no es, sin embargo, tan obvio. Otros han creído poder relacionar sus motivos con una posible presencia bien griega arcaica (Bendala, 1977 y 1983), bien fenicia (Blázquez, 1987) o con una naciente organización estatal en el Suroeste (Barceló, en prensa). Finalmente, en alguna ocasión (Fernández Miranda y Pereira, en prensa), se ha señalado asimismo su relación con vías de paso. En todas estas distintas interpretaciones subsiste sin embargo un elemento común: la creencia generalmente compartida de que las estelas del Suroeste se asocian a enterramientos y que se habrían usado como lápidas de las sepulturas, o como marcador vertical de la situación de las mismas.

En este trabajo se expone una visión contraria. 1) Que las estelas no son tumbas ni están relacionadas con tumbas, aunque no se niega un posible significado funerario-conmemorativo. 2) Por tanto, que su misión no es señalar lugares de enterramiento sino ser hitos visibles a distancia para la gente que se mueve por el territorio. 3) Que marcan recursos importantes para un grupo humano que, como los ganaderos y los comerciantes, se desplazan periódicamente, cuales son caminos, puertos, vías de paso, ríos y recursos de agua... etc. 4) Que habitualmente se sitúan en el punto de contacto entre dos zonas de contraste ecológico, como pueden ser el valle y la sierra, y que han podido delimitar fronteras entre territorios o áreas de diferente aprovechamiento económico.

\section{LAS ESTELAS DEL SUROESTE Y LOS ENTERRAMIENTOS DEL BRONCE FINAL}

Como se señaló anteriormente, es creencia generalizada que las estelas del Suroeste corresponden o están asociadas a enterramientos. Ello es debido en gran parte a la necesidad, consciente o inconsciente, que siente el arqueólogo de rellenar el total vacío de información funeraria en el Suroeste durante el Bronce Final; a la creencia de que tienen que existir muertos y tumbas, puesto que hay evidencia de ocupación y asentamiento en el territorio correspondiente. De ahí que aquéllas, la inmensa mayoría por otra parte, que no aparecen asociadas a restos arqueológicos y, en especial, a tumbas, se consideren descontextualizadas, lo que no tiene necesariamente que responder a la realidad, sino al prejuicio previo con el que han sido estudiadas, esto es, a la idea de que deben estar asociadas a una necrópolis o, al menos, a una tumba.

Por el contrario, si analizamos los cuatro únicos casos en que se menciona su presunta asociación a un enterramiento, veremos que la información es ambigua e incluso claramente rechazable.

Así ocurre en el de la primera y más famosa de las estelas conocidas, la de Solana de Cabañas, de la que Almagro Basch (1966: 27) relata que «estaba sobre una sepultura, a su vez cubierta con piedras sueltas, amontonadas sobre ella formando un majano". Es decir, que tanto la estela como las piedras que la cubrían no estaban en posición, pero no procedían de lejos. Según el mencionado autor, la supuesta sepultura había sido excavada en tierra firme (¿la base para la substentación de la estela en vertical?) y añade que aunque los halladores informaron de la existencia de ligeras cenizas, como de esqueleto humano, indudablemente se trataba de una inhumación.

Nuevamente los prejuicios previos actúan a la hora de realizar la interpretación y lo hacen doblemente. De acuerdo con la teoría de la época, los pueblos incineradores son los de Campos de Urnas, mientras que en la tradición indígena del Occidente predomina la inhumación. Por lo tanto, no sólo debe tratarse de un enterramiento - primera asunción subjetiva一, sino que éste debe considerarse, pese a la mención de cenizas por parte de los halladores, como «ligeros restos de un esqueleto humano" —segunda asunción subjetiva- (Ibídem: 27).

En el segundo caso, el de Granja de Céspedes, Almagro Basch (1966: 105 y 107) considera nuevamente que se trata con seguridad de una sepultura de inhumación, en la que la estela podría haber estado primitivamente de pie, habiéndose derrumbado con posterioridad aplastando el supuesto cadáver enterrado y del que se habrían encontrado restos muy descompuestos. No obstante el 
relator del hallazgo no asistió al mismo y únicamente nos cuenta que se le entregó una cajita conteniendo los escasos trozos del presunto cadáver que, "por su nulo valor antropológico, dado su estado de fragmentación y descomposición" , no fueron conservados...

En este punto es preciso recordar no sólo las teorías vigentes sobre pueblos inhumadores e incineradores, sino asimismo como Almagro Basch recoge en el mismo corpus ya mencionado, las relativas a las estelas del Suroeste y losas alentejanas como continuación de una tradición de enterramiento. Así, y puesto que aparentemente las losas cubren enterramientos de inhumación en cista, las estelas del Suroeste deben hacerlo igualmente. Esta es la idea aún imperante en nuestros días.

De la tercera estela aparentemente relacionada con un enterramiento, la sevillana de Setefilla, nos dice nuevamente Almagro Basch (1974 : 324-330) que fue hallada en el suelo entre los túmulos I y $G$ de la necrópolis, cubriendo una fosa de inhumación que contenía urnas, huesos calcinados y un esqueleto humano. Todo parece indicar una reutilizacion posterior de la estela en una necrópolis que, como sabemos, es orientalizante. Esta impresión puede verse confirmada en los datos que proporciona el mismo autor, en el sentido que la estela mostraba una pátina diferenciada en su parte inferior, de lo que se infiere que su posición original era diferente a la del momento de su hallazgo.

Queda por último un cuarto caso de reciente publicación, localizado fuera de la Península Ibérica: el de la estela de Salen (Buoux, Vaucluse) en la Provenza francesa (Müller, Bouville y Lambert, 1988). De élla se nos relata que apareció tumbada boca abajo, con huellas de arado en la parte posterior -es decir, no estaba en posición-, en un área de manchas cenicientas. Los publicadores mencionan en relación con élla, aunque sin especificar claramente en el texto su exacta asociación, si la había, un enterramiento masculino, en este caso por incineración y contenido en el interior de un vaso de características propias de los Campos de Urnas. Es decir, que en el supuesto de que hubiera una asociación entre estela y enterramiento, extremo que no se especifica en la publicación, se daría la transposición de un ritual de enterramiento en una tradición cultural y ritual diferente, la de Campos de Urnas.

Con excepción de esos cuatro casos, tan dudosos por otra parte, ninguna de las restantes 65 estelas recogidas por nosotros implica la menor asociación a enterramiento, lo que, repetimos, no significa necesariamente que todas ellas se hayan encontrado fuera de su situación original, sino que posiblemente se las ha considerado así porque no se asociaban a un contexto funerario al cual, creemos, nunca pertenecieron.

Si por el contrario analizamos estas estelas desde una perspectiva más amplia, la de su pertenencia al mundo del Bronce Final Atlántico, esta ausencia de enterramientos arqueológicamente visibles no es, sin embargo, excepcional ni única en la parte atlántica peninsular, sino general al Bronce Final de toda la fachada atlántica europea (Bradley, 1990; Ruiz-Gálvez, en prensa a).

Así, en el Noroeste de la Península Ibérica, la zona de más antigua tradición de contactos atlánticos, tras los enterramientos en cista emparentables con los de Wessex I y la Primera Serie de Túmulos Armoricanos (Ruiz-Gálvez, 1984a y en prensa a) no vuelven a registrarse nuevos hallazgos de enterramientos, hasta el punto que algún autor como G. Pereira (1984: 283) llega a afirmar: "Diríase que hasta la llegada de los romanos no hubiera muertos en Galicia». Y lo mismo podría decirse del Norte de Portugal, donde tal vacío de hallazgos se ha querido cubrir con la identificación como tumbas de las fosas abiertas en el granito descompuesto, o xabre en portugués, repetidamente interpretadas por S. Jorge como necrópolis (Martins y Jorge, en prensa), donde a falta de restos de enterramientos y de ajuares homogéneos, cabe considerar otras posibles interpretaciones, como ofrendas culturales e, incluso, como basureros. También se ha alegado (Kalb y Höck, 1979) que ciertos monumentos megalíticos de la región pudieron haberse reutilizado en el Bronce Final, basándose en la presencia como hallazgo aislado de algún fragmento cerámico o de algún objeto de bronce. No obstante, su falta de asociación a restos humanos admite otro tipo de interpretación, no necesariamente funeraria.

En el estuario del Tajo se conoce un único enterramiento para todo el Bronce Final, el de Roça

$$
\text { T. P., 1991, no } 48
$$


do Casal do Meio (Spindler y Veiga, 1973), cuyos ajuares y tipo de enterramiento son totalmente ajenos al mundo occidental y tienen, por el contrario, un marcado sabor mediterráneo, por lo que Almagro Gorbea (1986) lo interpreta en el contexto de las navegaciones precoloniales hacia Occidente y M. Belén y J. L. Escacena (en prensa) en idéntico sentido, como sepulturas de ocasión.

En la Extremadura española, si descartamos como enterramientos las estelas del Suroeste, no conocemos otra evidencia de tumbas que las de la necrópolis de Valcorchero (Almagro Gorbea, 1977), difíciles de datar por la ausencia de restos humanos o de cualquier tipo de ajuar, y porque la forma de la sepultura - la cista - tiene una larga tradición en el Bronce Pleno del Suroeste.

En cuanto al Suroeste, recientes excavaciones y revisiones (Aubet et al., 1983; Ruiz-Gálvez, 1984b; Escacena y De Frutos, 1986; Belén y Escacena, en prensa; Ruiz-Gálvez, en prensa a) han permitido replantear la secuencia propuesta por Schubart (1975). Así, el Bronce II del Suroeste no puede remontarse más allá de lo que convencionalmente conocemos como Bronce Medio. Tras el Bronce II del Suroeste, como recientemente señalaban Belén y Escacena (en prensa), no se conocen tumbas en la región, e incluso escasean en la Edad del Hierro, fenómeno que igualmente se repite en el resto de la fachada atlántica peninsular, así como en otras regiones atlánticas como Sur de Inglaterra o Bretaña (Bradley, 1990; Ruiz-Gálvez, en prensa a).

Frente a esta paulatina desaparición de enterramientos arqueológicamente visibles en la región atlántica europea a partir del Bronce Medio y ya claramente en el Bronce Final, es notoria también la presencia de armas, en especial espadas, en las aguas de los ríos o entre las fisuras de las rocas en las mismas regiones. Fenómeno que podría estar asociado a un ritual de paso (Ruiz-Gálvez, 1982; Bradley, 1990) al que tal vez en ocasiones pudo acompañar la deposición de restos humanos en las aguas (Bradley y Gordon, 1988). Ello respondería a un mundo funerario e ideológico común a la región atlántica occidental (Ruiz-Gálvez, en prensa a) y explicaría la ausencia de toda documentación funeraria en la región.

\section{LAS ESTELAS DEL SUROESTE COMO HITOS}

Vinculado a las consideraciones precedentes se halla el tema de la posición que originalmente presentarían las estelas durante su momento de uso.

Todos los autores coinciden desde un principio en que al menos la mayor parte de éllas estarían hincadas, señalando la sepultura de un guerrero de alto rango. Pero, dentro de una aparente uniformidad de criterio, no todos están de acuerdo con que ésta sea la única posición posible.

En su síntesis de 1966, Almagro diferenciaba las estelas extremeñas o del tipo II de sus predecesoras alemtejanas, o del tipo I, entre otras razones por su diferente colocación, afirmando que las primeras "por la estructura de su decoración, (...) parece que puede deducirse que estuvieron hincadas sobre la tumba de aquél a quien se consagraron", añadiendo que ésto sucedería "en las antropomórficas que son todas alargadas, si no están rotas" (Almagro, 1966: 201). Por el contrario, las estelas no antropomórficas, es decir, las que sólo presentan armas, pudieron servir como lápidas tendidas sobre las sepulturas, a semejanza de sus antecesoras alemtejanas.

Posteriormente Almagro Gorbea recoge esta interpretación, si bien considera que los casos en los que la estela pudiera haber estado originalmente dispuesta a modo de losa son ciertamente más dudosos (Almagro Gorbea, 1977: 193). Ese mismo año, Varela y Pinho afirmaban ya que en todas las estelas entonces conocidas y en buen estado de conservación (14 de un total de 27), se reservaba sin decorar al menos la cuarta parte inferior. De ello deducían, sin hacer excepciones, que las estelas "debían estar situadas verticalmente, con la parte inferior hundida en el suelo» (Varela y Pinho, 1977: 183).

Actualmente el número de estelas conocidas se ha elevado considerablemente y es posible realizar precisiones que aporten una mayor certeza a este respecto, concluyéndose que la posición 
de las estelas fue en todos los casos la vertical, con el objeto de ser visibles desde una cierta distancia.

Como decimos, y puede verse en el gráfico adjunto (Fig. 1), disponemos hoy de una muestra de 69 estelas. Separando de ese número total las 26 estelas dañadas en su parte inferior, podemos decir que la totalidad de las 43 estelas restantes, que conservan con claridad, íntegra o parcialmente, su tercio inferior, presentan este espacio reservado sin decoración. Este hecho por sí mismo ya parece implicar un factor determinante en la composición de todas las estelas que podemos considerar completas, pero si en el seno de este grupo efectuamos un análisis más detenido apreciaremos que hay aún más elementos de juicio para aceptar la verticalidad de todas las estelas.

Efectivamente, aunque 29 de esas 43 estelas no poseen otra característica más definitoria de su posición erguida que ese tercio inferior reservado, las restantes 14 aportan datos claros y definitorios de su concepción para ser utilizadas en posición vertical.

Por un lado tres de ellas conservan aún una pátina diferencial en ese tercio inferior, que delata que estuvieron hincadas. Son éstas las de San Martinho II (Almagro, 1966), Setefilla (Almagro, 1970) y Almoharín (Ongil, 1983).

Otra más, la estela de San Martinho I (Almagro, 1966) presenta claramente el pie marcado intencionalmente al ser tallada.

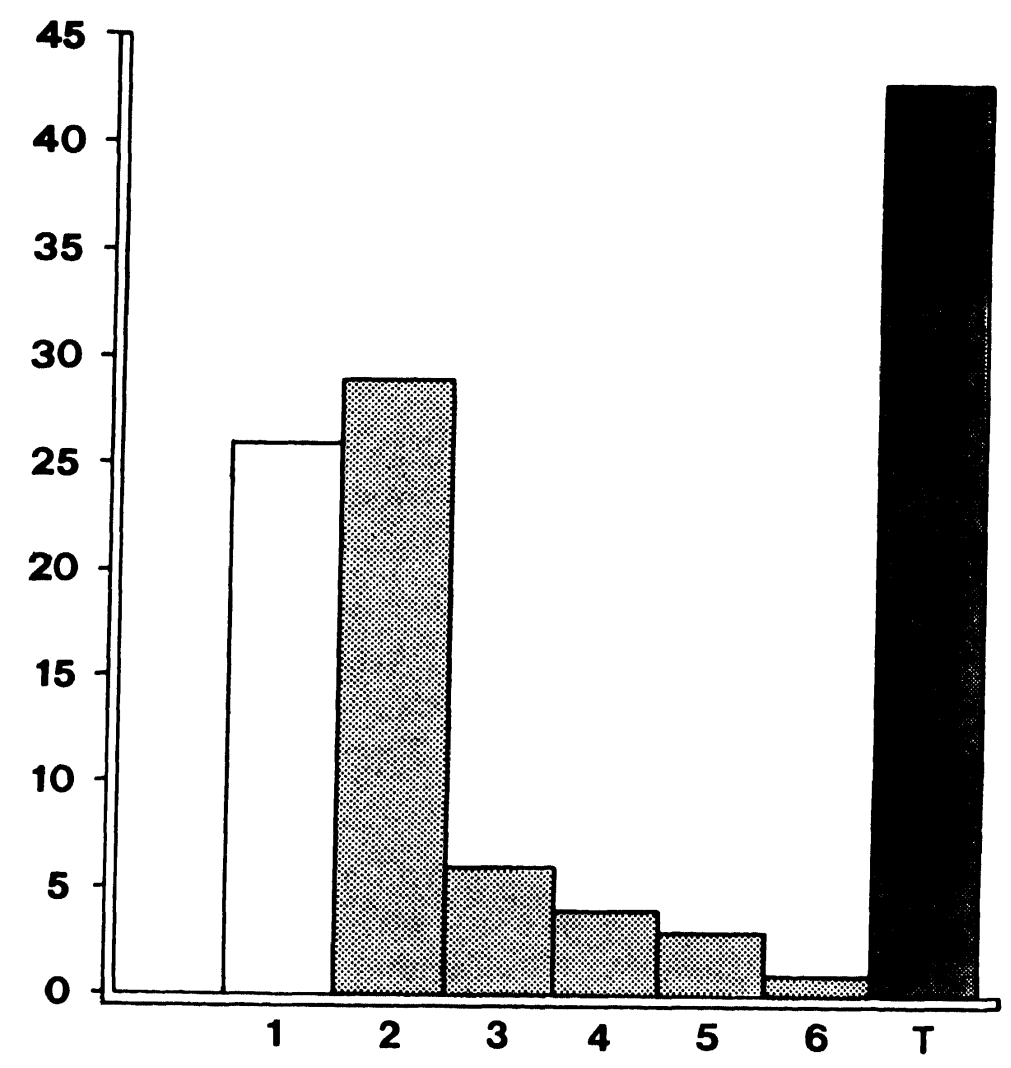

FIG. 1.-Demostración gráfica de la verticalidad de las estelas según el análisis de su tercio inferior. 1.- Estelas a las que falta la parte inferior; 2.- Estelas con la zona inferior reservada; 3.- Estelas con la zona inferior reservada y sin desbastar; 4.- Estelas con la zona inferior reservada y rematada en punta; 5.- Estelas con la zona inferior reservada y con pátina; 6. - Estelas con la zona inferior reservada y con pie marcado; 7.- Total de las estelas que están concebidas para ser hincadas. 
Cuatro estelas rematan en pico o punta claramente preparados o, al menos, aprovechados para facilitar la posición vertical hincada en tierra. Estas son las de Ategua (Almagro , 1970), Zarza de Montánchez (Almagro Gorbea y Sánchez, 1978), Belalcázar (Enríquez y Celestino, 1984) y La Lantejuela (Oliva, 1983).

Finalmente seis estelas más presentan esta zona inferior sin desbastar, en contraste con la preparación o aprovechamiento de superficies planas que preside las zonas superiores decoradas. En este grupo se incluyen las de San Martín de Trevejo (García de Figuerola, 1982), Capilla III (Vaquerizo, 1985), Baraçal (Curado, 1984), Valdetorres (Enríquez y Celestino, 1984), Las Herencias (Fernández-Miranda, 1986) y Aldea del Rey I (Valiente y Prado, 1977-78), uniendo ésta última a dicha cualidad la de rematar también en pico.

Haciendo un breve resumen numérico, las estelas que no han perdido su parte inferior suponen el $62,25 \%$ del total recogido, un tercio de las cuales presenta rasgos inequívocos de su concepción para ser utilizadas verticalmente, manteniendo las dos terceras partes restantes ese espacio inferior sin decoración, rasgo también significativo de su colocación original.

De todos estos datos creemos que se deduce con claridad que la posición natural de las estelas extremeñas era la vertical, lo que siempre sugirió su estructura decorativa, sobre todo en el caso de las estelas con representaciones humanas.

Una consecuencia natural de las razones expuestas hasta el momento - que las estelas no se corresponden con enterramientos y que su posición natural es la vertical- es la de preguntarse cuál es entonces la función de este tipo de elementos, para qué se erigen.

Los datos de dispersión de las estelas muestran que al menos una parte de ellas, once en total, fueron halladas en cerros o lomas. Son éstas las que mejor evidencian la función primordial de las estelas, que es la de ser visibles desde una considerable distancia. Estas estelas son:

- Las tres de San Martinho, en la loma del mismo nombre y junto a la ermita de Nuestra Señora de Mercoles (Almagro, 1966: 34 y 36 ).

- Las tres también de Valencia de Alcántara, halladas en la finca "Las Mayas» y de las que se dan vagas referencias a su situación en la ladera de un cerro y sobre una loma (Ibídem: 110-14).

- La estela de Ecija I, hallada en el Cerro Perea, junto al propio pueblo (Almagro, 1974: 13) y la de Ecija II en la Atalaya de Moranilla, ocho km. al NE. del mismo (Rodríguez y Núñez, 1983-84: 289 y 294).

- La estela de San Martín de Trevejo, encontrada en la ladera Norte del Cerro de la Manta, a unos $150 \mathrm{~m}$. de la cumbre, en una pendiente de suave descenso hacia el valle (García de Figuerola, 1982: 173).

- La estela de Valdetorres, desenterrada en un alto denominado el Cerro del Santo, junto al depósito de agua del pueblo (Enríquez y Celestino, 1984: 241).

- Y finalmente la estela de Montemolín, que parece haber sido hallada a unos 150 o $200 \mathrm{~m}$. de la cumbre del más alto de los montículos o tells del cortijo del mismo nombre, sobre la ladera Norte del mismo (Chaves y De La Bandera, 1982: 137).

Se ha dudado reiteradamente de que muchas de estas estelas se encuentren en su lugar original o a poca distancia. Almagro supone que las estelas de San Martinho no estaban in situ, argumentando que las excavaciones realizadas en torno suyo no proporcionaron ningún vestigio. Con el argumento contrario Rodríguez y Núñez sostienen la misma hipótesis para la de Ecija II, sosteniendo que al haber sido hallada, como la de Montemolín, en un área en la que se detectan restos de habitación humana en la Antigüedad, han debido ser reutilizadas y por tanto descontextualizadas.

Si examinamos separadamente los aspectos implicados en estas hipótesis veremos que en ningún caso son concluyentes. En principio se basan en la presunción, como ya vimos infundada, de que las estelas son elementos funerarios, por lo que a uno extraña no encontrar restos de los enterramientos y a otros su aparición en un contexto habitacional. Por otro lado resulta difícil pensar, al menos en el caso de San Martinho, por qué alguien, que no lo hiciese con ese propósito, se habría molestado en trasladar las éstelas hasta lo alto del cerro, ya que se nos indica que aparecieron aisladas, sin 
indicios de haber sido reutilizadas. Si aceptamos que estamos hablando de hitos para ser vistos desde la distancia, no debiera extrañar que la inmensa mayoría carezca de cualquier contexto arqueológico inmediato, pues posiblemente jamás lo tuvieron.

\section{LAS ESTELAS Y SU SITUACION CON RESPECTO A LOS CAMINOS Y VIAS DE PASO}

Hemos visto como un cierto número de estelas se sitúan en lugares elevados, dotados de una buena visibilidad. Por otro lado, podemos observar como la mayoría de las estelas cuya procedencia se puede constatar con fiabilidad se localizan cerca de accidentes geográficos de gran valor para el control de zonas de paso, cuales son los caminos naturales que siguen el curso de ríos o arroyos, los vados que permiten atravesar fácilmente esos cursos fluviales o los puertos que favorecen el paso de las sierras interiores de la Península. Algunas de las estelas reúnen a su alrededor varias de estas características, junto al control de puntos de agua, como pozos, y zonas de pasto para el ganado, convirtiéndose así en emplazamientos privilegiados en el seno del paisaje que ocupan (Fig. 2).
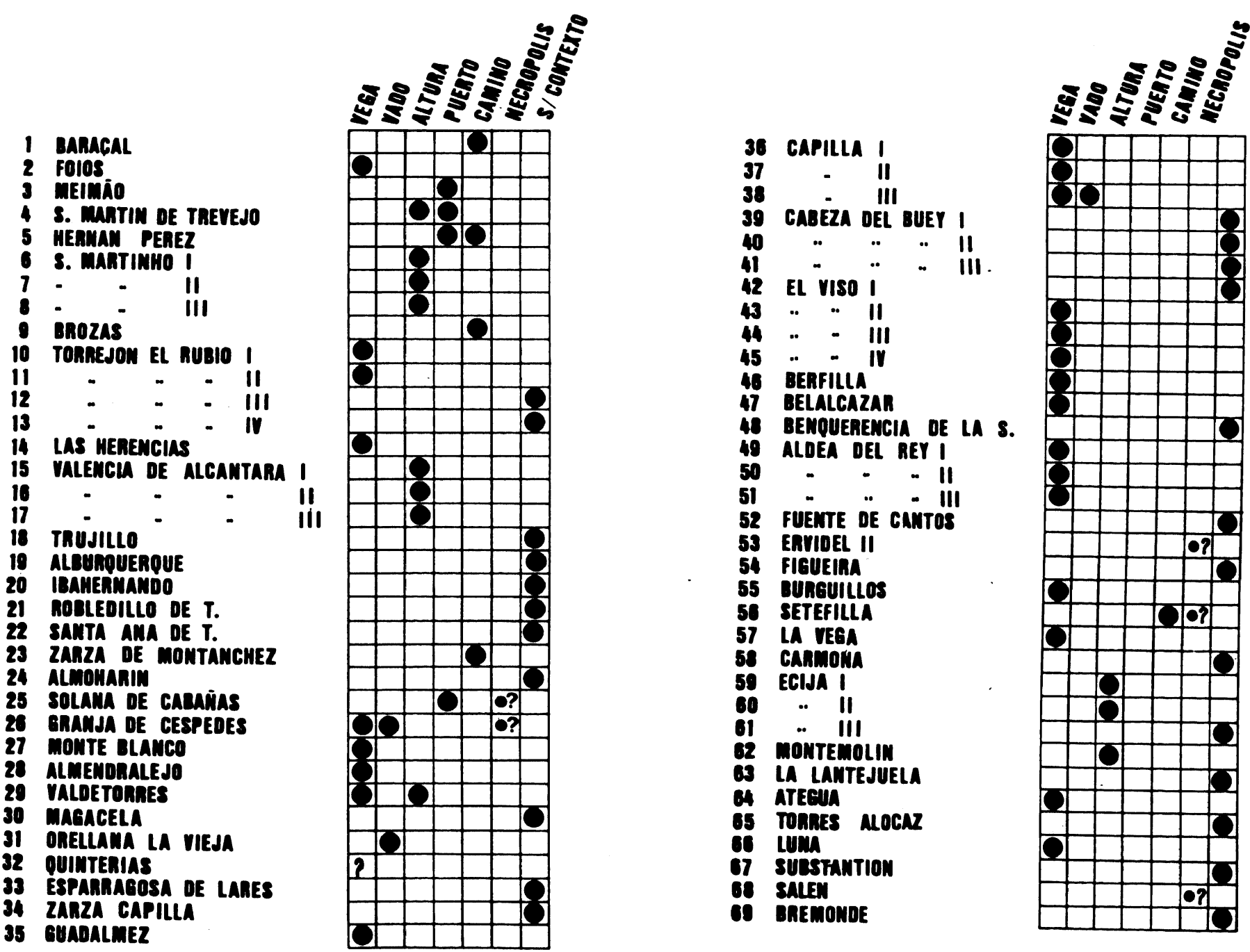

Fig. 2.-Cuadro resumen de dispersión de las estelas del Suroeste en relación vías o áreas de paso (según la situación de las mismas dada por cada autor). 
Estas cualidades se pueden apreciar también en muchas de las localizaciones de estelas de las que se nos dice que carecen de contexto, pero que aparecen en vegas fluviales o en las cercanías de vías principales ya conocidas desde la Antigüedad. Ya hemos expresado nuestras reservas sobre el prejuicio que subyace en los criterios empleados hasta ahora para determinar cuando una estela se encuentra fuera de contexto. Admitiendo que muchos de los ejemplares "descontextualizados" se hallan en su lugar de origen o sólo muy levemente desplazados, como los recogidos en lindes o majanos, podemos apreciar como las estelas se concentran principalmente en las márgenes de la cuenca de los grandes ríos del Suroeste peninsular - Tajo, Guadiana y Guadalquivir - y de algunos de sus afluentes. Las dos principales concentraciones registradas se sitúan precisamente en las zonas de paso entre esas cuencas: en la Sierra de Montánchez, entre el Tajo y el Guadiana, y en torno al río Zújar, entre el Guadiana y el Guadalquivir.

Tomando, pues, como punto de partida la dispersión de las estelas y considerándolas hitos que reflejan la frecuentación de determinados caminos y que controlan territorios concretos, apreciamos tentativamente la existencia de dos grandes vías, cada una de las cuales presenta variantes y bifurcaciones, y entre las que existe una amplia zona de contacto. Consideramos estas posibles vías como hipótesis de trabajo, que en todo caso deberán ser confirmadas por la investigación posterior. Cabe aclarar que la concepción de las estelas como hitos no implica necesariamente su posición a orillas de un camino determinado, pues su función es, a nuestro parecer, marcar recursos en relación con esas rutas, pero no delimitarlas. No se trata de mojones viales, pero dado que están concebidas como elementos de referencia visual en el paisaje, parece lógico deducir su relación con zonas de paso.

Una primera vía enlazaría la parte occidental del Sistema Central con el Bajo Guadalquivir, mientras la segunda, más oriental, partiendo desde el valle medio del Tajo, se dirigiría al valle del Guadalquivir en el área de Córdoba (Fig. 3).

En relación con este esquema viario cobraría sentido la situación de la estela de Luna (Fatás, 1975), siguiendo el valle del Tajo aguas arriba, derivando por sus afluentes, Jarama y Henares, hacia el valle del Ebro por el del Jalón y remontando luego el río Gállego, a cuyas orillas se encontró la estela. Este camino se halla marcado por hallazgos del Bronce Atlántico en el corazón de la Meseta Oriental, como las espadas de Sigüenza o la de Alhama de Aragón, que indican una penetración del comercio de este signo en las regiones del interior, por el mismo camino que luego seguirá el hierro aparecido en la Muela de Alarilla (Méndez y Velasco, 1988) y las cerámicas pintadas (véase la Fig. 4).

La Primera ruta discurriría atravesando el Sistema Central por las estribaciones más occidentales de la Sierra de Gata, en las que se emplazan las estelas de Foios y Baraçal (Curado, 1984 y 1986), ambas en el distrito de Sabujal, que aparece ya en el "Repertorio de todos los caminos de España" de P. J. Villuga en 1546 como parte del camino natural que desde la fachada atlántica se dirigía a Salamanca y las llanuras del Duero, a sólo $81 / 2$ leguas castellanas (unos $47 \mathrm{~km}$.) de Ciudad Rodrigo, ya en las dehesas salmantinas. Fernández-Miranda y Pereira (en prensa) indican que por aquí discurría uno de los tradicionales caminos de la Mesta.

Atravesando después el puerto de Meimâo, donde se sitúa otra estela (Almagro, 1966), y siguiendo el valle del Ponsul, se llegaría a las cercanías de Castelo Branco, donde se hallaron las tres estelas de San Martinho (Ibídem), como dijimos sobre una loma que domina el entorno.

La Sierra de Gata puede también cruzarse alternativamente por otros puertos algo más orientales y de mayor altitud. Entre éllos están los de Trevejo, donde apareció la estela de San Martín de Trevejo (G. de Figuerola, 1982), y el valle del río Tralgas, en cuya salida meridional de la Peña de Francia se encuentra la estela de Hernán Pérez (Almagro, 1972). Este es el camino a través de Las Hurdes, jalonado por significativos topónimos viales y pecuarios como Pinofranqueado, Caminomorisco (Fernández-Miranda y Pereira, en prensa) y, en la salida septentrional, Las Mestas y que constituye un paso paralelo a occidente al del puerto de Béjar. El hecho de que la estela de San Martín de Trevejo se hallase en la ladera Norte del cerro de la Manta, y en unas condiciones que hacen pensar que estuviese en su lugar original (G. de Figuerola, 1982: 173), así como el que tanto ésta como la de Hernán Pérez se localicen en la parte meridional de los puertos de la Sierra de 


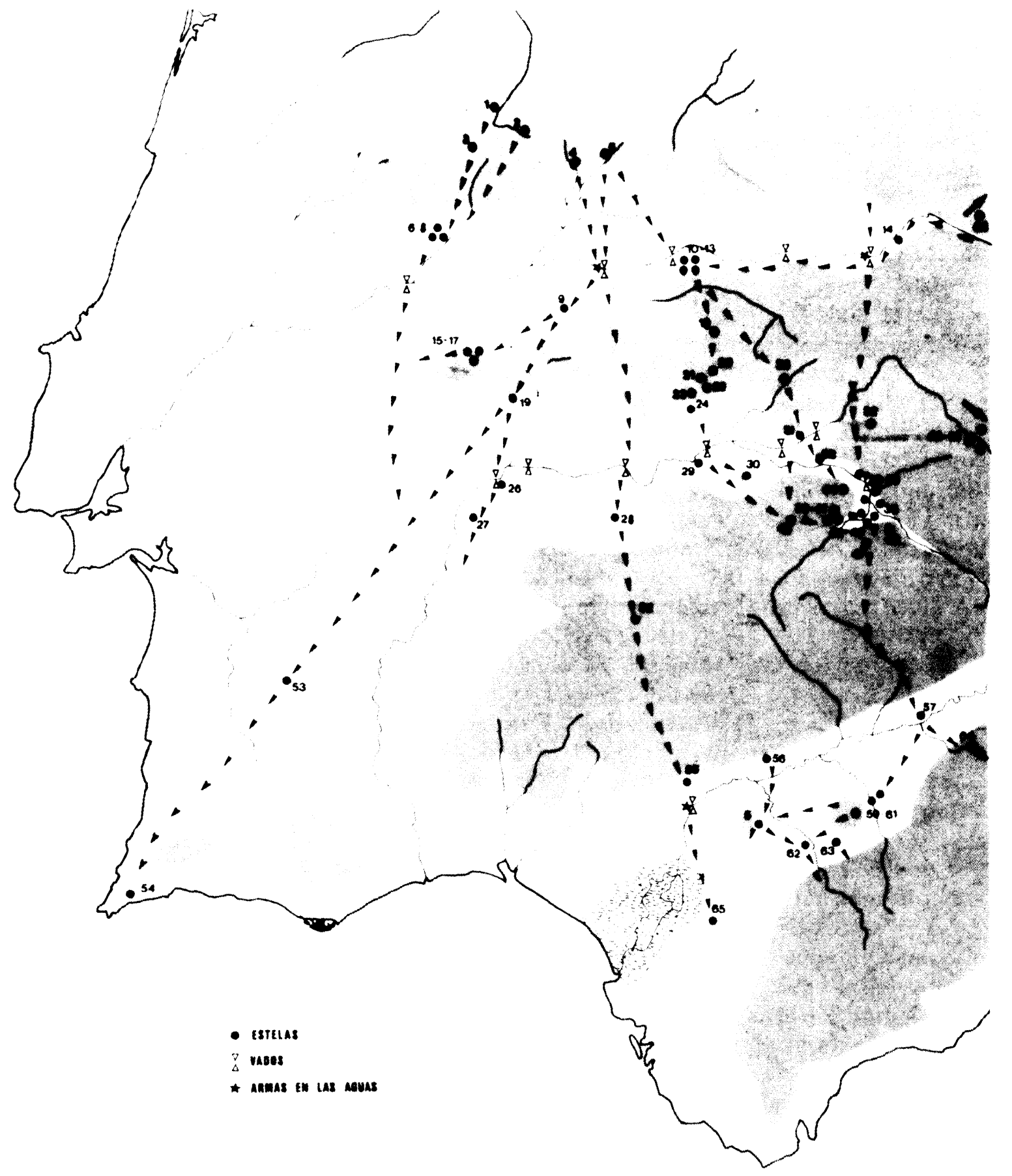

FIG. 3.-Dispersión de las estelas del Suroeste en relación con las vías ganaderas y comerciales. 1.- Baraçal; 2.- Foios; 3. - Meimá; 4.- San Martín de Trevejo; 5.- Hernán Pérez; 6.- San Martinho I; 7.- San Martinho II; 8.- San Martiho III; 9. - Brozas; 10. - Torrejón el Rubio I; 11.- Torrejón el Rubio II; 12.- Torrejón el Rubio III; 13.- Torrejón el Rubio IV; 14.- Las Herencias; 15. - Valencia de Alcántara I; 16.- Valencia de Alcántara II; 17.- Valencia de Alcántara III; 18. Truiillo; 19.- Albuquerque; 20.- Ibahernando; 21.- Robledillo de Trujillo; 22.- Santa Ana de Trujillo; 23. - Zarza de Montánchez; 24.- Almoharín; 25.- Solana de Cabañas; 26.- Granja de Céspedes; 27.- Monte Blanco; 28.- Almendralejo; 29.- Valdetorres; 30.- Magacela: 31.- Orellana la Vieja; 32. - Quinterías; 33.- Esparragosa de Lares; 34.- Zarza Capilla; 35.- Guadalmez; 36. - Capilla I; 37.- Capilla II; 38. - Capilla III; 39.- Cabeza del Buey I; 40.- Cabeza del Buey II; $41 .-$ Cabeza de Buey III; 42. - El Viso I; 43.- El Viso II; 44. - El Viso III; 45.- El Viso IV; 46. - Berfilla; 47.- Belalcázar; 48.- Benquerencia de la Serena; 49. - Aldea del Rey I; 50.- Aldea del Rey II; 51.- Aldea del Rey III; 52. - Fuente de Cantos; 53.- Ervidel II; 54.- Figueira; 55. - Burguillos; 56.- Setefilla; 57.- La Vega Córdoba; 58. - Carmona; 59.- Ecija I; 60. - Ecija II; 61.- Ecija III; 62.- Montemolin; 63. - La Lantejuela; 64.- Ategua; 65.- Torres Alocaz; 66.- Luna. 


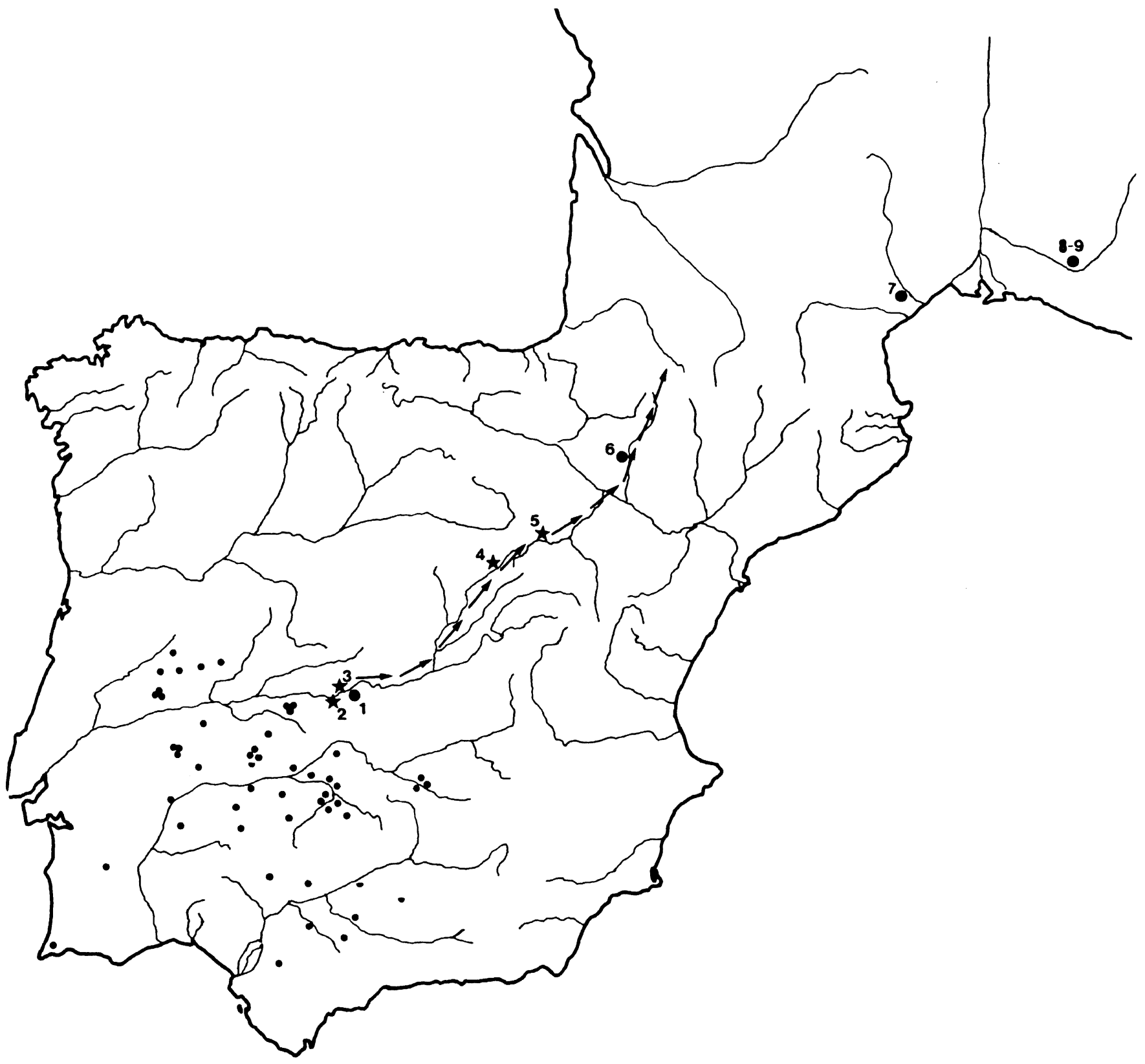

Fig. 4.-La ruta natural entre el Suroeste y la estela de Luna, y la situación de las estelas francesas. 1.- Estela de Las Herencias; 2.- Espada de El Carpio; 3.- Espada de Azután; 4.- Espadas de Sigüenza; 5.- Espada de Alhama de Aragón; 6.- Estela de Luna; 7.- Estela de Substantion; 8.- Estelas de Salen y Bremonde.

Gata, parece indicar que están concebidas para servir de referencia a quien desciende desde las tierras al Norte del Sistema Central hacia Extremadura, muy probablemente conduciendo el ganado hacia las dehesas meridionales.

La información etnográfica vendría a reforzar esta idea, pues hasta hace muy poco tiempo, para la gente que habitaba las estribaciones septentrionales de la sierra de Gredos, las tierras extremeñas a las que descendían estacionalmente con sus rebaños representaban una tierra de promisión (Kavanagh, 1987).

Una vez traspasado el Sistema Central el camino afrontaba el cruce del Tajo, río que, por correr

T. P., 1991, no 48 
muy encajado en su cauce, of rece pocos vados a lo largo de gran parte de su recorrido, lo que les convierte en puntos altamente estratégicos. Podemos destacar entre la información que nos proporcionan los antiguos itinerarios el paso de barcas de Montalvâo, directamente al Sur de Castelo Branco, recogido por Villuga (1546), y el conocido vado de Alconétar en Cáceres, con el que se relaciona un hallazgo de espada, probablemente funerario (Ruiz-Gálvez, 1982) en las aguas (Almagro Gorbea, 1977). Del señalado valor estratégico de este vado da cuenta el hecho de que por el mismo pasaba la Vía de la Plata y, en época moderna, el camino de Sevilla a Valladolid de acuerdo con Villuga, cruzándose desde la Edad Media en barca (Hernández, 1967), una vez quedó fuera de uso el puente construido por los romanos. Además el Vado de Alconétar se sitúa en el eje de la falla de Plasencia, que crea un camino natural que enfila por el Noreste hacia el puerto de Tornavacas, y hacia el Suroeste, pasado el Tajo, por las cercanías de Brozas y Alburquerque, donde se sitúan sendas estelas (Almagro, 1966). De la importancia de este camino natural da perfecta cuenta el trabajo de Alvarez y Gil (1988), fundamentalmente en relación con el periodo orientalizante.

También era posible el cruce del Tajo por otros vados más orientales, como los de Serradilla, Montfragüe y Albalat, que conducen directamente a la vega en que se asienta Torrejón el Rubio, con cuatro estelas recogidas (Almagro, 1966; Ongil, 1983). De Torrejón el Rubio hacia el Sur aparece como enclave importante Trujillo, en cuyas cercanías conocemos la estela del Cortijo del Carneril (Almagro, 1974), y desde allí toda la concentración de estelas que marcan la ruta de cruce de la Sierra de Montánchez, un poco al Oeste del Puerto de Santa Cruz. Estas estelas son las de Ibahernando, Santa Ana y Robledillo de Trujillo (Almagro, 1966), Zarza de Montánchez (Almagro Gorbea y Sánchez Abal, 1978) y, en las estribaciones meridionales de la sierra, la de Almoharín (Ongil, 1983).

Desde Almoharín se emboca directamente el vado de Medellín, uno de los más importantes puntos de cruce del Guadiana, no muy lejos del cual, y dominando el terreno desde el cerro del Santo, se encuentra la estela de Valdetorres (Enríquez y Celestino, 1984).

Retomando la ruta más occidental que habíamos abandonado antes, el camino hacia el Sur aparece jalonado por las estelas de Alburquerque, Granja de Céspedes (Almagro, 1966), situada junto a un vado del Guadiana en las cercanías del río Caia (Hernández, 1967), y Monte Blanco de Olivenza (Bueno y Piñón, 1985). Algo al Norte de Alburquerque parece partir una bifurcación hacia el Oeste a través del paso entre dos sierras que permite Valencia de Alcántara, donde se conocen tres estelas (Almagro, 1966). Recordemos además que estas estelas parecen hallarse situadas en alto, favoreciendo su mejor visibilidad.

Dentro también de esta vía más occidental cabría situar la estela relativamente lejana de Ervidel II (Varela y Pinho, 1977), aparentemente tan aislada, pero que vista dentro del conjunto aquí descrito, significaría un hito más en la ruta transhumante hacia las dehesas del Bajo Alemtejo, en el extremo Occidente peninsular, coincidiendo su situación con la prolongación hacia el Suroeste del eje geomorfológico creado por la falla de Plasencia, antes comentada.

Entre los dos grandes ramales de esta primera ruta queda precisamente el camino tradicionalmente conocido como Vía de la Plata, en el que apenas se pueden situar actualmente tres estelas. De Norte a Sur son las de Arroyo Bonaval en Almendralejo y Fuente de Cantos (Almagro, 1966), en las estribaciones septentrionales de la Sierra Morena, una vez rebasado el Guadiana a través del vado de Mérida, y finalmente la de Burguillos (Rodríguez, 1983) en las estribaciones meridionales de la misma Sierra, lindando ya con la vega del Guadalquivir y de frente al Vado de las Estacas, junto a Alcalá del Río, de donde también proceden diversos hallazgos de armas en las aguas (Ruiz-Gálvez, 1984a; Ruiz, 1988). Cabe recordar que el de las Estacas es el último vado antes de la desembocadura del Guadalquivir, muy cercana en este momento a juzgar por las reconstrucciones realizadas para el estuario del río en época protohistórica (Caro, 1989). Con la desembocadura apenas un poco al Sur de la propia Sevilla, se comprenderá mejor la situación casi costera de la última y más meridional de las estelas conocidas, la de Torres Alocaz (Oliva y Chasco, 1976). Ello quizás explique tambien la localización de la estela de Figueira, cerca de la costa, y enlazando en Ervidel con la ruta más occidental que acabamos de describir. 
La Segunda ruta que proponemos seguiría un camino prácticamente lineal desde el curso medio del Tajo hasta el Valle Medio del Guadalquivir a la altura de Córdoba, aunque como veremos también pueden apreciarse bifurcaciones en diversos sentidos.

Sobre el Tajo encontramos primeramente la estela de Las Herencias (Fernández-Miranda, 1986; Fernández-Miranda y Pereira, en prensa), muy cercana al vado de Azután, donde se localizan también hallazgos en las aguas, una espada rota en lengua de carpa procedente de El Carpio (Jiménez, 1966) y otra pieza inédita a la altura del propio vado. Siguiendo el curso del río, conectaríamos con un punto ya conocido en la primera vía, Torrejón el Rubio, donde la diversidad de estelas puede ser, más que indicio de evolución cronológica, aunque ésto no sea descartable, síntoma de la confluencia de dos redes viarias distintas.

Siguiendo hacia el Sur desde el área de Las Herencias-Azután y rebasando los Montes de Toledo por el Puerto de San Vicente, accederíamos a la ribera del Guadiana por el camino entre Castilblanco y Talarrubias, donde se cita otro vado (Hernández, 1967), no lejos del cual queda la estela de Quinterías (Vaquerizo, 1989). Un poco más al Oeste es también posible cruzar el río por los vados de Casas de D. Pedro y Orellana la Vieja, sitio este último donde se localiza otra estela más (Enríquez, 1982b). Aún antes de vadear el Guadiana el puerto de Berzocana permite el acceso a esta ruta desde Torrejón el Rubio, estando situada muy cercana al pie del puerto la estela de Solana de Cabañas (Almagro, 1966).

Siguiendo la ruta más directa hacia el Sur, una vez cruzado el Guadiana por Castilblanco, nos encontraríamos con el valle del Zújar y su concentración de estelas. En un espacio bastante reducido se situan las tres estelas de Capilla (Enríquez y Celestino, 1981-82; Vaquerizo, 1985), la de Zarza Capilla (Enríquez, 1982a), la de Guadalmez (Ruiz, 1986), las tres de Cabeza del Buey (Almagro, 1966; Almagro Gorbea, 1977), las cuatro de El Viso (Almagro Gorbea, 1977; Bendala, Hurtado y Amores, 1979-80; Iglesias, 1980a y 1980b), la de Berfilla (Bueno, Piñón et al. 1984), y las de Belalcázar y Esparragosa de Lares (Enriquez y Celestino, 1984). Algunas de estas estelas están situadas claramente en relación con el control de los vados del río Zújar. En concreto sabemos de la existencia cercano a Capilla de un vado, precisamente junto al cual, reseñado en el Mapa Topográfico Nacional (Hoja 781, Siruela. Escala 1: 50.000) como Vado de Trigueros, se localiza una de las estelas aparecidas en ese término municipal. Junto a Esparragosa de Lares el Diccionario de Madoz (1847. T. 7) señala la existencia, aún en el siglo XIX, de una barca y un pontón para el cruce de ganados transhumantes. Este vado era conocido en época musulmana con el significativo nombre de "Vado de Córdoba» (Hernández, 1967).

Entre algunas de estas estelas pueden establecerse incluso relaciones de intervisibilidad, y su aparición concentrada en este tramo montañoso sólo tiene explicación por tratarse del único camino posible más o menos directo desde el Noroeste hacia la zona cordobesa del Guadalquivir, permitiendo en algunas zonas tomar bifurcaciones interesantes, en concreto las que desde Cabeza del Buey permiten acceder al Valle de la Serena, donde conocemos la estela de Benquerencia (Enríquez, 1982a), o dirigirse hacia Medellín, en cuyo punto intermedio se halla Magacela (Almagro, 1966).

Al sur de Belalcázar, apenas si se puede seguir otro camino que el angosto valle del Guadiato para acceder a las cercanías de Córdoba. Por otro lado las estelas encontradas en Aldea del Rey (Valiente y Prado, 1977-78 y 1979) permiten suponer la existencia de un camino hacia el Valle del Guadalquivir por la Alta Andalucía, situándose Aldea del Rey en las cercanías de los caminos que en época moderna se dirigían de Córdoba a Toledo dejando a occidente los Montes de Toledo (Villuga, 1546), y en el cruce de varios cordeles ganaderos importantes.

Quedan, pues, por explicar dos áreas complementarias a estas vías Norte-Sur. Por un lado el sentido de las estelas del Valle del Guadalquivir. Por otro las lejanas estelas del Sureste francés.

Las estelas andaluzas del Valle del Guadalquivir presentan una dispersión claramente periférica, con la única excepción de la recientemente publicada estela de La Vega de Córdoba (Morena y Núñez, 1990). Setefilla, en las primeras estribaciones de Sierra Morena al Norte el Valle, tiene una 
perfecta coherencia con la tesis aquí expuesta, ya que es un claro punto de paso de cordeles ganaderos (Aubet et al. 1983), cuya relación con la Meseta está suficientemente atestiguada.

Por otro lado las estelas de la vertiente meridional del valle se distribuyen siguiendo la vía Córdoba-Sevilla por Ecija (Almagro, 1974; Rodríguez y Núñez, 1983-84 y 1985) y Carmona (Almagro, 1966), mientras las más alejadas, Montemolín (Chaves y La Bandera, 1983), La Lantejuela (Oliva, 1983) y Ategua (Almagro, 1970) parecen mostrar una tendencia común en dirección al área malagueña, una de las zonas de dehesa importantes de la Península.

Más problemático resulta actualmente situar y, sobre todo, comprender dentro de este conjunto los hallazgos franceses de Substantion en el Languedoc (Almagro, 1966) y Buoux en Provenza (Müller, Bouville y Lambert, 1988). La primera parece estar reutilizada en un oppidum muy posterior, en la cuenca del Herault, mientras las de Salen y Bremonde se sitúan en la cuenca de uno de los principales afluentes del Ródano desde los Alpes. A pesar de los problemas que su hallazgo tan lejano del núcleo de las estelas grabadas supone, cabe resaltar que en ambos casos parecen controlar ríos, las principales vías de comunicación en la Prehistoria, especialmente en una zona como ésta, donde la cordillera alpina se extiende casi hasta la costa.

\section{ESTELAS, HITOS Y CAMINOS}

Hemos analizado las estelas del Suroeste en relación con las posibles vías sobre las que se sitúan, indicando su función de hitos o marcadores de recursos para las gentes que se mueven por el territorio. Un análisis más profundo de la vinculación de las estelas con recursos determinados requeriría un trabajo detallado y de mayor extensión que el que puede llevarse a cabo en estas páginas, y está en la actualidad siendo desarrollado por uno de nosotros (Galán Domingo, en preparación).

De cualquier forma, una visión de conjunto de la distribución de las estelas del Bronce Final, permite comprobar que la mayor parte de ellas están situadas al pie de puertos de montaña, en las zonas de menor altitud entre dos sierras o en las inmediaciones de la única elevación existente en la zona, o bien en zonas de vega, cercanas a vados de ríos, pero generalmente a cierta distancia de los mismos, o ya en el contacto entre la vega y las elevaciones que la circundan. Quizás el caso más claro lo constituye el grupo de estelas del Valle del Guadalquivir, la mayor parte de las cuales se encuentran situadas en los primeros resaltes orográficos que circundan la cuenca y alguno de sus afluentes, como el Genil o el Corbones.

Esta tendencia general a limitar áreas de contraste geográfico debe ser tenida en cuenta a la hora de explicar el papel que las estelas del Suroeste jugaron durante su período de utilización, por cuanto constituyen zonas naturalmente fronterizas entre espacios de aprovechamiento diferenciado, tal vez opuesto, tal vez complementario, señalando así posibles fronteras territoriales. En todo caso la reiteración de similitudes en el patrón de distribución elimina cualquier posibilidad de pensar que se trate de situaciones no perseguidas conscientemente por aquéllos que erigieron las estelas.

Un caso similar lo constituyen las llamadas «piedras de héroe» de la India (Thapar, 1981). Como posiblemente las estelas del Suroeste, las piedras de héroe son monumentos conmemorativos en los que se recuerda a un guerrero muerto en combate, bien en una guerra o en el curso de un ataque contra su territorio por parte de asaltantes o de ladrones de ganado. Las estelas tienen un valor deificador del difunto y refuerzan con el culto a éste la cohesión del grupo, pero a la vez son susceptibles de otra lectura por su situación. Igualmente aparecen en zonas de contraste geográfico o de aprovechamiento del suelo (entre pastos y cultivos), a la vez que son periféricas al territorio político de un grupo, pues éstas son las zonas de mayor conflictividad. Un tercer aspecto de semejanza puede ser el de la representación, pues la categoría del guerrero viene marcada por los atributos que porta en su representación, lo que nos lleva a considerar la posibilidad de ver la decoración de las estelas del Suroeste como una forma de lenguaje heráldico, en el que se 
suministra al que las observa informaciones sobre la importancia del personaje o grupo que controla el territorio cuyos recursos marca, e incluso sobre el tamaño del territorio de éste (Galán Domingo, en preparación).

Otro dato, que únicamente apuntamos aquí, es la relación territorial existente entre las estelas y otros elementos culturales del Bronce Final del mismo área, como los hallazgos áureos de Sagrajas, cerca de un vado junto a Badajoz, Berzocana, al pie del puerto del mismo nombre, Bélmez y Bodonal de la Sierra, en la vertiente norte de Sierra Morena, etc. Es importante observar también cómo tanto las estelas cómo los tesoros del Bronce Final rodean Cádiz y Huelva, zona nuclear del futuro reino de Tartessos, donde no se dan este tipo de hallazgos. Lo mismo puede decirse de la relación existente entre las armas arrojadas a las aguas, que hemos ido reseñando, y los vados de los ríos, relación que de ningún modo se puede considerar casual. En ese caso, habrá que poner las estelas en relación con la emergencia, en el hinterland tartéssico, de organizaciones políticas jerarquizadas.

En resumen, lo que nos gustaría destacar es la función de las estelas del Suroeste como marcadores de un control del territorio y de las vías de comunicación por las que discurren tanto los ganados transhumantes como los productos comerciales $\mathrm{y}$, con éllos, personas e ideas que provocarán los grandes cambios que toda la región muestra a partir del impacto orientalizante en las costas meridionales (Helms, 1988).

Dos ejemplos de la importancia que el control de estas rutas adquiere en época inmediatamente posterior lo tenemos en las tumbas de El Carpio (Toledo) y La Aliseda (Cáceres). En ambos casos se trata, al parecer, de enterramientos femeninos con ricos ajuares orientalizantes. Todo induce a pensar que fueron princesas del Suroeste casadas con señores locales de los territorios que rodeaban el reino, reflejo de una política de intercambio de mujeres que, a través del establecimiento de lazos de parentesco entre jefes, garantiza la paz y la libre circulación por el territorio (Ruiz-Gálvez, en prensa b).

Los dos enterramientos comentados se sitúan en el curso de rutas que permiten la conexión entre el Suroeste propiamente dicho, y las tierras a partir del Norte del río Tajo. La tumba del Carpio de Tajo (Pereira y Alvaro, 1955 y 1990) apareció muy cercana a la estela de las Herencias y al vado de Azután, en el inicio de una de las vías desde la Meseta hacia el Suroeste, a la vez que punto de conexión de ésta con la que penetraba en la Meseta Oriental por el sistema Henares-Jalón y desde allí se dirigía, a través del Valle del Ebro, hacia el Pirineo, explicando, en nuestra opinión, la localización de la estela de Luna. La tumba de La Aliseda (Almagro Gorbea, 1977) se localiza también en un importante nudo de caminos, por un lado en el cruce de la Sierra de San Pedro, divisoria entre las cuencas del Tajo y del Guadiana, y por otro sobre el camino entre Cáceres y Portugal.

Otro ejemplo, esta vez situado en el Sureste peninsular, puede apoyar la idea de las estelas como elementos hincados y concebidos para ser vistos desde cierta distancia. Es éste el monumento turriforme de Pozo Moro (Almagro Gorbea, 1978), situado sobre un antiguo pozo, como su nombre aún recuerda, y en un cruce de caminos entre las rutas de Cartago-Nova a las regiones ganaderas de la Meseta Central, con la Vía Herakleia, que unía el Valle del Guadalquivir con el Sureste y Levante (Ibídem: 258).

En este caso parece claro que se trata de una construcción monumental, concebida para ser vista a gran distancia y servir de referencia'a aquellos que transitaban por las vías en cuyas inmediaciones se sitúa. Es, claramente, un signo del poder de quien lo erigió y tiene también un significado de identificación de un grupo humano con el territorio que ocupa.

En conclusión, en este trabajo se han expuesto las siguientes ideas:

1) Que la función de las estelas del Suroeste no es la de servir de lápida o marcador vertical de enterramientos del Bronce Final.

2) Que hay que considerar a estas estelas como hitos situados en las inmediaciones de las vías,

T. P., 1991, n 48 
fundamentalmente de transhumancia, que unen las tierras del Sistema Central, e incluso más al Norte, con las dehesas del Suroeste.

3) Que su función especifica es la de marcar recursos importantes para las gentes que se desplazan por esas vías (pastos, vías de paso, agua), señalando el control de tales recursos por un grupo determinado.

4) Que no es aleatoria su colocación entre áreas de contraste geográfico y de aprovechamiento del suelo, y que muy posiblemente pueden ayudarnos a delimitar el territorio de los distintos grupos humanos de la región.

5) Que a pesar de no ser tumbas sí pueden estar relacionadas con el mundo funerario en el sentido de conmemoración o heroización del difunto. Idea que pudo transponerse al mundo orientalizante y de época ibérica donde monumentos funerarios, aquí claramente tumbas, se utilizan como referencias visibles en el paisaje para quien se traslada por un territorio.

\section{BIBLIOGRAFIA}

Almagro Basch, M. (1966): Las estelas decoradas del Suroeste peninsular. Bibliotheca Praehistórica Hispana, VIII. Madrid.

- (1970): «Dos nuevas estelas decoradas en Andalucía Occidental» Actas del XI Congreso Nacional de Arqueología (Mérida, 1968): 315-331. Zaragoza.

- (1972): "Los ídolos y la estela decorada de Hernán Pérez (Cáceres) y el ídolo estela de Tabuyo del Monte (León)" Trabajos de Prehistoria, 29: 83-124.

- (1974): «Nuevas estelas decoradas de la Península Ibérica». Miscelánea Arqueológica, I: 5-39.

Almagro Gorbea, M. (1977): El Bronce Final y el Periodo Orientalizante en Extremadura. Bibliotheca Praehistórica Hispana, XIV. Madrid.

- (1978): «Los relieves mitológicos orientalizantes de Pozo Moro». Trabajos de Prehistoria, 38: 251 -278.

- (1986): "Bronce Final y Edad del Hierro. La formación de las etnias y culturas prerromanas» en F. Jordá et al. Prehistoria: 341-532. Madrid. Ed. Gredos.

Almagro Gorbea, M. y Sánchez Abal, J. L. (1978): "La estela decorada de Zarza de Montánchez (Cáceres)». Trabajos de Prehistoria, 35: 417-423.

Alvarez Rojas, A. y Gil Montes, J. (1988): "Aproximación al estudio de las vías de comunicación en el primer milenio antes de Cristo en Extremadura». Trabajos de Prehistoria, 45: 305-316.

Aubet, M. E.; Serna, M. R.; Escacena, J. L. y Ruiz Delgado, M. (1983): La Mesa de Setefilla, Lora del Rio (Sevilla). Campaña de 1979. Excavaciones Arqueológicas en España, 122. Madrid.

Barceló, J. A. (1989): "Las estelas decoradas del Sudoeste de la Península Ibérica" en M. E. Aubet Tartessos. Arqueología Protohistórica del Bajo Guadalquivir: 189-208. Ed. Ausa. Sabadell.

- (En prensa): "La transición de economías tribales a la estratificación: el estudio del suroeste de la Península Ibérica durante el Bronce Final». Trabajos de Prehistoria. 49, 1992.

Beltrán Lloris, M. y Alcrudo, C. (1973): «Noticia de dos nuevas estelas decoradas del Museo de Cáceres». Estudios, II: 81-93.

BelÉN, M. y Escacena, J. L. (en prensa): «Las comunidades prerromanas de la Baja Andalucía». I Congreso de Paleoetnología de la Península Ibérica. Madrid, Diciembre de 1989.

Bendala Galán, M. (1977): “Notas sobre las estelas decoradas del Suroeste y los orígenes de Tartessos». Habis, 8: 177-205.

- (1983): «En torno al instrumento musical de la estela de Luna (Zaragoza)». Homenaje al prof. Martín Almagro Basch. II: $141-146$.

Bendala Galán, M.; Hurtado, V. y Amores, F. De (1979-80): «Tres nuevas estelas de guerreros en la provincia de Córdoba". Habis, 10-11: 381-390.

Blázouez Martínez, J. M. (1987): «Los escudos con escotadura en V y la presencia fenicia en la costa atlántica y en el interior de la Península Ibérica». Actas del IV Coloquio sobre lenguas y culturas paleohispánicas (Veleia 2-3): 469-497.

Bradley, R. (1990): The passage of arms. An archaeological analysis of prehistoric hoards and votive deposits. Cambridge University Press. Cambridge.

BradLey, R. y GoRdON, K. (1988): «Human skulls from the river Thames, their dating and significance». Antiquity, 62. 
Bueno Ramírez, P.; Piñón Varela, F.; Torres, F.; Rodriguez, J. J. y Gutiérrez, F. (1984): “Tres nuevas estelas del Suroeste». Revista de Estudios Extremeños, XL, 3: 477-483.

Bueno Ramirfz, P. y Piñón Varela, F. (1985): "La estela de Monte Blanco, Olivenza (Badajoz)" Homenaje a Jesús Cánovas Pesini: 37-43. Badajoz.

Caro Bellido, A. (1989): "Consideraciones sobre el Bronce Antiguo y Medio en el Bajo Guadalquivir» en M. E. Aubet (coord.) Tartessos. Arqueología Protohistórica del Bajo Guadalquivir. Ed. Ausa. Sabadell.

Curado, F. P. (1984): "Uma nova estela do bronze final na Beira Alta (Baraçal, Sabugal-Guarda)». Arqueologia, 9: 81-85. Porto.

- (1986): "Mais uma stela do bronze final na Beira Alta (Foios, Sabugal-Guarda)». Arqueologia, 14: $103-109$. Porto.

Chaves Tristán, F. y de la Bandera Romero, M. L. (1982): "Estela decorada de Montemolín (Marchena, Sevilla)». Archivo Español de Arqueología, 55: 137-147.

Enríuez Navascués, J. J. (1982a): “Dos nuevas estelas de guerreros en el Museo Arqueológico Provincial de Badajoz". Museos, 1: 65-68.

- (1982b): "Una nueva estela de guerrero y tres asadores de bronce procedentes de Orellana la Vieja (Badajoz)". Museos, 2: 9-13.

Enríquez Navascués, J. J. y Celestino Pérez, S. (1981-82): “La estela de Capilla (Badajoz)». Pyrenae, 17-18: 203209.

- (1984): «Nuevas estelas decoradas en la cuenca del Guadiana». Trabajos de Prehistoria, 41: 237-250.

Escacena, J. L. y DE Frutos, G. (1985): "Estratigrafía de la Edad del Bronce en el Monte Berrueco (Medina Sidonia, Cádiz)». Noticiario Arqueológico Hispánico, 24.

FatÁs CABEZA, G. (1975): "Una estela de guerrero con escudo escotado en "V", aparecida en las Cinco Villas de Aragón". Pyrenae, 11: 165-169.

Fernández-Miranda Fernández, M. (1986): "La estela de Las Herencias (Toledo)». Estudios en Homenaje al Dr. Antonio Beltrán Martínez: 463-476. Zaragoza.

Fernández-Miranda, M. y PEREIRA, J. (en prensa): “Indigenismo y orientalización en la tierra de Talavera».

García de Figuerola, M. (1982): "Nueva estela decorada del tipo II en San Martín de Trevejo (Cáceres)». Zephyrus, 34-35: 173-180.

Helms, M. (1988): Ulysses'Sail. An ethnographic Odysey of power, knowledge and geographical distance. Princeton. University Press. Princeton

HERnÁNDEZ GimÉnEZ, F. (1967): "Los caminos de Córdoba hacia Noroeste en época musulmana». Al-Andalus, 32, 1 y $2: 37-123$ y $277-358$.

Iglesias Gil, J. L. (1980a): «Estela inédita hallada en El Viso (Córdoba)». Archivo Español de Arqueología, 53: 189. 193.

- (1980b): «Nueva estela decorada procedente del Viso (Córdoba)». Zephyrus, 30-31: 254-256.

JimÉnEZ DE GREgorio, F. (1965): "Hallazgos arqueológicos en la provincia de Toledo» Archivo Español de Arqueología, 38: 174-186.

Kalb, Ph. y Hock, M. (1979): "Ausgrabunger in der Grabhügelnekropole Fonde da Malga (Viseu, Portugal)». Madrider Mitteilungen, 20.

KavanaGH, W. (1987): «Extremadura en la cosmovisión de los ganaderos transhumantes de la vertiente norte de la Sierra de Gredos». Revista de Estudios Extremeños, XLIII, 3: 751-757.

Madoz, P. (1847): Diccionario geogáfico-estadístico-histórico de España y sus posesiones de Ultramar. Tomo 7.

Martins, M. y Jorge, S. O. (en prensa): «Substrato cultural das etnias prerromanas do Norte de Portugal». I Congreso de Paleoetnología de la Península Ibérica. Madrid, Diciembre de 1989.

Méndez Madariaga, A. y Velasco Steigrad, F. (1988): "La Muela de Alarilla». Actas del Primer Congreso de Historia de Castilla-La Mancha. III: 185-195. Ciudad Real.

Morena López, J. A. y Muñoz Muñoz, J. F. (1990): «Nueva estela de guerrero del Bronce Final hallada en Córdoban. Revista de Arqueología, 115: 14-15.

Müller, A.; Bouville, C. y LamberT, L. (1988): «Provence. Les steles gravees de l'Age du Bronze». Archeologia, 236 (Junio): 58-63.

Oliva Alonso, D. (1983): "Una nueva estela antropomorfa del Bronce Final en la provincia de Sevilla". Homenaje al profesor Martín Almagro Basch. II: 131-139.

Oliva Alonso, D. y Chasco Vila, R. (1976): "Una estela funeraria con escudo de escotadura en «U» en la provincia de Sevilla». Trabajos de Prehistoria, 33: 387-395.

Ongil Valentín, M. I. (1983): «La estela decorada de Almoharín». Vettonia: 5-13.

Pereira Menault, G. (1984): “La formación histórica de los pueblos del Norte de Hispania. El caso de Gallaecia como paradigma». Veleia, 1.

Pereira, J. y De Alvaro, E. (1988): «Una tumba de la transición Bronce-Hierro en la Meseta Sur: El Carpio (Belvís de la Jara, Toledo)m. Actas del Primer Congreso de Historia de Castilla-La Mancha. III: 279-289.

- (1990): "El enterramiento de la Casa del Carpio, Belvís de la Jara (Toledo)». Actas del Primer Congreso de Arqueología de la provincia de Toledo: 215-234. Toledo.

PINGEL, V. (1974): «Bemerkungen zu den ritverzierten stelen und zur beginnenden eisenzeit un Südwesten der Iberischen Halbinsel». Hamburgen Beiträge zur Archäologie, 4: 1-19. 
Rodríguez Hidalgo, J. M. (1983): «Nueva estela decorada en Burguillos (Sevilla)». Archivo Español de Arqueologia, 56: $229-234$.

Rodríguez Temiño, I. y Núñez Pariente de León, E. (1983-84): "Una segunda estela del Bronce Final hallada en Ecijan. Pyrenae, 19-20: 289-294.

- (1985): "La tercera estela del Bronce Final hallada en Ecija». Habis, 16: 481-485.

Ruiz Delgado, M. M. (1988): «Un nuevo depósito de armas del Bronce Final en el río Guadalquivir». Trabajos de Prehistoria, 45: 273-279.

Ruiz LaRA, D. (1986): "Nueva estela decorada en el valle del Zújar». Estudios de Prehistoria Cordobesa, 1: $95-101$.

Ruiz Gálvez Priego, M. (1982): «Nueva espada dragada en el río Ulla. Armas arrojadas a las aguas». El Museo de Pontovedra XXXVI. Homenaje a Alfredo García Alén.

- (1984a): La Península Ibérica y sus relaciones con el circulo cultural atlántico. Universidad Complutense. Madrid.

- (1984b): «Consideraciones terminológicas acerca de la Edad del Bronce peninsular». Trabajos de Prehistoria, 42.

- (En prensa a): «Canciones del muchacho viajero». Veleia.

- (En prensa b): "Orientaciones teóricas sobre intercambio y comercio en Prehistoria». Gala, 1.

SCHUBART, H. (1975): Die Kultur del Bronzezeit im Südwestern der Iberischen Halbinsel. Madrider Forchungen.

SPINDLER, K. y VeIGA, O. DA (1973): «Der Spätbronzezeitliche Kuppelbau von der Roça do Casal do Meio, in Portugal». Madrider Mitteilungen, 12.

ThaPAR, R. (1981): "Death and the Hero". En S. C. Humphreys y H. King (eds.) Mortality and Inmortality: The Anthropology and Archaeology of Death. Academic Press: 293-315. Londres.

Valiente Malla, J. y Prado Toledano, S. (1977-78): «Estelas decoradas de Aldea del Rey (Ciudad Real)». Archivo Español de Arqueología, 50-51: 375-388.

- (1979): «Nueva estela decorada de Aldea del Rey (Ciudad Real)». Archivo Español de Arqueología, 52: 27-32.

Vaquerizo GIL, D. (1985): "Dos nuevas estelas de guerrero en la provincia de Badajoz». Actas del XVII Congreso Nacional de Arqueología (Logroño, 1983): 465-472. Zaragoza.

- (1989): «Estelas de guerreros en la protohistoria peninsular: la estela de Quinterías». Revista de Arqueología, 99: 29-38.

Varela Gomes, M. y Pinho Monteiro, J. (1977): “Las estelas decoradas do Pomar (Beja, Portugal). Estudio comparado". Trabajos de Prehisuria, 34: 165-214.

Villuga, P. J. (1546): Repertorio de todos los caminos de España. Medina del Campo. Edición Facsímil de 1950. 